ISSN : 2549-2314;

Volume : 1 ; Number 1

\title{
PENGARUH WAKTU INTERAKSI BENTONIT TERAKTIVASI TERHADAP DAYA SERAP IODIUM
}

\author{
M. Machfud ${ }^{\star}$, Rusmini \\ Jurusan Kimia, Universitas Negeri Surabaya, Ketintang, Surabaya, 60231, Indonesia \\ *Corresponding author, email: machfudmuhammad89@yahoo.co.id \\ Co-author 1, email: rusminiadjis@gmail.com
}

\begin{abstract}
A study on the influence of $\mathrm{H}_{2} \mathrm{SO}_{4}$-activated bentonite interaction time against the adsorption of iodine has been accomplished. The purpose of this study was to investigate the characteristics of $\mathrm{H}_{2} \mathrm{SO}_{4}$-activated bentonite, and determine the effect of $\mathrm{H}_{2} \mathrm{SO}_{4}$-activated bentonite interaction time on the adsorption of iodine. Characterization of activated bentonite was analyzed using BUCK 500 Infrared spectrophotometer and Philips X'Pert X-ray diffractometer. In order to determine the effect of $\mathrm{H}_{2} \mathrm{SO}_{4}$-activated bentonite interaction time on the adsorption of iodine, iodometric titration method was conducted. The results showed that the characteristics of activated bentonite from PT. Madu Lingga Raharja with an infrared spectrophotometer at wavenumber of $3439.9 \mathrm{~cm}^{-1}$ indicates the $\mathrm{OH}$ group stretching vibration of water molecules, the wavenumber of $1035.7 \mathrm{~cm}^{-1}$ represents the Si$\mathrm{O}$ stretching vibration of Si-O-Si, while the wavenumber of $924.9 \mathrm{~cm}^{-1}$ exhibits the $-\mathrm{OH}$ vibrations of Al-OH on octahedral layer. Its chemical composition is Montmorillonite, Quartz and Halloysite. The optimum time of iodine adsorption with bentonite at concentration of $400 \mathrm{ppm}$ was 30 minutes, and the adsorption percentage was $23.5 \%$, while the optimum time of iodine adsorption with bentonite at concentration of $100 \mathrm{ppm}$ was 60 minutes, and the adsorption percentage was $38.44 \%$.
\end{abstract}

Keywords: adsorption; activated bentonite; iodine

\section{ABSTRAK}

Telah dilakukan penelitian tentang pengaruh waktu interaksi bentonit teraktivasi $\mathrm{H}_{2} \mathrm{SO}_{4}$ terhadap daya serap iodium. Tujuan dari penelitian ini untuk mengetahui karakteristik bentonit teraktivasi $\mathrm{H}_{2} \mathrm{SO}_{4}$, serta untuk mengetahui pengaruh waktu interaksi bentonit teraktivasi $\mathrm{H}_{2} \mathrm{SO}_{4}$ terhadap daya serap iodium. Karakterisasi bentonit teraktivasi $\mathrm{H}_{2} \mathrm{SO}_{4}$ diuji dengan spektrofotometer Infra Merah BUCK 500 dan difraktometer sinar X Philips X'pert. Untuk mengetahui pengaruh waktu interaksi bentonit teraktivasi $\mathrm{H}_{2} \mathrm{SO}_{4}$ terhadap daya serap iodium dilakukan dengan metode titrasi iodometri. Hasil penelitian menunjukkan bahwa karakteristik bentonit aktif dari PT Madu Lingga Raharja dengan spektrofotometer inframerah pada bilangan gelombang 3439,9 $\mathrm{cm}^{-1}$ menunjukkan vibrasi ulur gugus -OH dari molekul air, bilangan gelombang 1035,7 $\mathrm{cm}^{-1}$ menunjukkan vibrasi ulur $\mathrm{Si}-\mathrm{O}$ dari Si-O-Si, bilangan gelombang 924,9 $\mathrm{cm}^{-1}$ menunjukkan vibrasi $\mathrm{OH}$ dari $\mathrm{Al}-\mathrm{OH}$ pada lapisan oktahedral. Komposisi kimianya adalah Montmorillonit, Quartz dan Halloysite. Adapun waktu optimum adsorpsi iodium dengan bentonit pada konsentrasi 400 ppm adalah 30 menit yaitu sebesar $23,5 \%$, sedangkan waktu optimum adsorpsi iodium dengan bentonit pada konsentrasi 100 ppm adalah 60 menit yaitu sebesar $38,44 \%$.

Kata Kunci: adsorpsi; bentonit teraktivasi; iodium 


\section{PENDAHULUAN}

Saat ini kebutuhan iodium meningkat dengan pesat karena fungsinya yang sangat beragam antara lain digunakan masyarakat sebagai obat antiseptik. lodium juga digunakan sebagai campuran pada garam untuk meningkatkan kualitas garam tersebut yang selanjutnya akan dikonsumsi oleh manusia. Penambahan iodium kedalam garam ini dapat mencegah penyakit gondok, badan kerdil, gangguan motorik, bisu, tuli dan keterbelakangan mental. lodium juga sangat dibutuhkan oleh industri farmasi sebagai bahan tingtur (pelapis obat)

Kebutuhan iodium di Indonesia sebagian masih diimpor dari beberapa Negara, salah satunya dari Jepang. Berdasarkan penelitian potensi sumber iodium di Indonesia yang belum dieksplorasi masih tersebar di berbagai daerah. Berdasarkan perkiraan potensi yang ada, maka diperlukan pengambilan dan pengolahan iodium secara efektif dan efisien untuk memenuhi kebutuhan yang ada.

Berdasarkan fakta lapangan yang ditemukan peneliti, sebuah PT dalam memproduksi iodium menggunakan proses oksidasi. Air sumber yang ditambang dari kedalaman 600-800 m dialirkan menuju kolam penampung. Sebelum sampai ke kolam penampung air tambang diberi oksidator dengan tujuan memisahkan iodium dengan senyawa-senyawa lain. Dari kolam penampung, air dipompa ke bak adsorpsi 1 dan direaksikan dengan $\mathrm{H}_{2} \mathrm{SO}_{4}$ untuk memberi suasana asam hingga mencapai $\mathrm{pH}$ 1,8-2,3 hal ini bertujuan untuk mengoptimalkan proses adsorpsi.
Di bak adsorpsi 2 proses adsorpsi iodium oleh karbon aktif berlangsung hingga karbon jenuh, setelah karbon jenuh yang ditandai dengan kadar iodium pada air limbah sebesar 2,5 ppm, proses adsorpsi dihentikan dengan cara menutup kran pipa yang mengalirkan air sumber ke bak adsorpsi. Proses selanjutnya adalah desorpsi. Proses ini dilakukan untuk mengambil iodium yang ada didalam karbon dengan bantuan $\mathrm{NaOH}$ dan air dengan suhu sekitar $40^{\circ} \mathrm{C}$. Setelah proses desorpsi selesai dilakukan proses pengendapan dengan menambahkan $\mathrm{NaNO}_{2}$ dan $\mathrm{H}_{2} \mathrm{O}_{2}$ yang dialirkan ke tangki pengendapan. Setelah proses pengendapan, proses terahir yaitu proses pemurnian dengan menambahkan $\mathrm{H}_{2} \mathrm{SO}_{4}$ pekat. Dari proses tersebut, adsorpsi iodium menggunakan adsorben karbon aktif untuk mengikat iodium yang terlepas dari senyawanya. Adsorben karbon dalam proses tersebut membutuhkan suasana asam dengan $\mathrm{pH}$ 1,8-2,3 agar bisa mengikat iodium secara sempurna.

Dari data yang diperoleh dari IPC (inproses control) efektifitas karbon yang digunakan sebagai adsorben dalam proses produksi adalah sebesar $21 \%$. Oleh karena itu perlu diupayakan alternatif adsorben lain yang diharapkan mampu lebih efektif menyerap iodium. Diantara jenis-jenis adsorben yang ada bentonit bisa menjadi alternatif pengganti karbon dalam proses adsorpsi iodium karena bentonit mempunyai pori yang besar dan harganya lebih murah dibanding karbon.

Bentonit merupakan material berpori yang memiliki kandungan mineral montmorillonit. Bentonit merupakan suatu jenis 
lempung berupa spesies silikat alumunium terhidrasi dengan sedikit substitusi. Aktivasi menggunakan asam bertujuan untuk menukar kation yang ada pada bentonit $\left(\mathrm{Na}^{+}\right.$dan $\left.\mathrm{Ca}^{2+}\right)$ dengan ion $\mathrm{H}^{+}$dan melepaskan ion $\mathrm{Al}, \mathrm{Fe}$ dan $\mathrm{Mg}$ dan pengotor-pengotor lainnya dari kisi-kisi struktur, sehingga secara fisiknya bentonit tersebut menjadi aktif. Aktivasi bentonit menggunakan asam mineral $\left(\mathrm{HCl}\right.$ dan $\left.\mathrm{H}_{2} \mathrm{SO}_{4}\right)$ akan meningkatkan daya adsorpsinya karena asam mineral tersebut akan bereaksi dan melarutkan komponen berupa tar, garam $\mathrm{Ca}$ dan $\mathrm{Mg}$ yang menutupi pori-pori bentonit [1]-[4] Disamping itu asam mineral melarutkan $\mathrm{Al}_{2} \mathrm{O}_{3}$ sehingga menaikkan perbandingan jumlah $\mathrm{SiO}$ dengan $\mathrm{Al}_{2} \mathrm{O}_{3}$.

Beberapa penelitian telah dilakukan untuk meningkatkan kemampuan bentonit sebagai adsorben. Pengaktivasian bentonit menggunakan $\mathrm{H}_{2} \mathrm{SO}_{4} \quad 1,5 \mathrm{M}$ pada kondisi optimum meningkatkan basal spacing dari 14,9167 Å menjadi 16,8857 ̊̊ [5] . Sementara itu pengaktivasian lempung menggunakan $\mathrm{H}_{2} \mathrm{SO}_{4}$ 1,2 $\mathrm{M}$ dapat meningkatkan situs aktif dari $3,0495 \times 10^{20}$ atom/gr menjadi 5,2608 X $10^{20}$ atom/gr [6]. Aktivasi lempung sebagai adsorben menggunakan $\mathrm{H}_{2} \mathrm{SO}_{4}$ pada kondisi optimal 1,2 M dapat menghasilkan luas permukaan spesifik dari $48,27 \mathrm{~m}^{2} / \mathrm{g}$ menjadi $65,21 \mathrm{~m}^{2} / \mathrm{g}$ [7]. Penggunaan karbon aktif sebagai adsorben untuk mengadsorpsi ion $\mathrm{Cu}^{2+}$, pada kondisi optimum waktu interaksi adalah 45 menit [8] . Berdasarkan hasil pra penelitian oleh peneliti penggunaan $4 \mathrm{gr}$ bentonit teraktivasi $\mathrm{H}_{2} \mathrm{SO}_{4}$ mampu menyerap iodium sebesar $30,01 \%$ dengan waktu interaksi selama 45 menit. Dari penelitian-penelitian tersebut maka peneliti meneliti efektifitas bentonit teraktivasi $\mathrm{H}_{2} \mathrm{SO}_{4}$ sebagai adsorben iodium.

\section{METODE}

\section{Material}

Lempung Na-bentonit diperoleh dari PT Madu Lingga Raharja di daerah Driyorejo, Gresik, Bahan-bahan kimia seperti $\mathrm{H}_{2} \mathrm{SO}_{4}$ pekat, $\mathrm{BaCl}_{2}, \mathrm{H}_{2} \mathrm{O}_{2}$, kloroform, natrium tiosulfat $0,01 \mathrm{~N}$, asam asetat $0,3 \mathrm{M}$, Aquades.

\section{Instrumentasi}

Spektrofotometer Infra Merah BUCK 500 digunakan untuk mendeteksi gugus fungsi dan perubahan struktur suatu molekul dan difraktometer sinar $X$ Philips X'pert yang digunakan untuk mengetahui derajat kristalinits mineral.

\section{Prosedur}

\section{Aktivasi Na-bentonit dengan asam}

Na-bentonit yang diperoleh dari PT Madu Lingga Raharja direndam dengan asam sulfat 1,5 $\mathrm{M}$ dengan perbandingan bentonitasam sulfat adalah 1:4. Diaduk dengan pengaduk magnet selama 6 jam. Lalu didiamkan selama 24 jam kemudian disaring dengan penyaring vakum dan dicuci dengan aquades sampai filtrat terbebas dari ion sulfat yang ditunjukkan dengan uji negatif terhadap $\mathrm{BaCl}_{2}$. Na-bentonit teraktivasi asam kemudian dikeringkan dalam oven pada suhu $110^{\circ} \mathrm{C}$. Setelah kering ditumbuk sampai menghasilkan ukuran bentonit 200 mesh. Produksi ini disebut dengan Na-bentonit aktif. 
Pembuatan Larutan $\mathrm{I}_{\mathbf{2}} \mathbf{1 0 0} \mathrm{ppm}$ dari Nal

Ditimbang $1,142 \mathrm{gr} \mathrm{Nal}$ kemudian dilarutkan dengan aquades sampai $1000 \mathrm{~mL}$. Larutan yang dihasilkan merupakan larutan $\mathrm{I}_{2}$ 1000 ppm. Untuk mendapatkan larutan $I_{2} 100$ ppm yaitu dengan cara mengambil $10 \mathrm{ml}$ larutan $l_{2} 1000$ ppm kemudian diencerkan sampai $100 \mathrm{ml}$ dengan aquades

\section{Pengujian Bentonit Teraktivasi $\mathrm{H}_{2} \mathrm{SO}_{4}$ Sebagai Adsorben $\mathrm{I}_{2}$}

Ditimbang bentonit teraktivasi $\mathrm{H}_{2} \mathrm{SO}_{4}$ sebesar 4 gr tiap- tiap variasi waktu yang dilakukan, kemudian dimasukkan pada $100 \mathrm{ml}$ larutan $\mathrm{I}_{2} 400 \mathrm{ppm}$ yang telah bibuat, kemudian distirer selama 15 menit, 30 menit, 45 menit, 60 menit, dan 75 menit. setelah itu disaring dengan penyaring vakum. Filtrat yang dihasilkan diberi $\mathrm{H}_{2} \mathrm{O}_{2} 10 \% 3 \mathrm{ml}, \mathrm{H}_{2} \mathrm{SO}_{4} 10 \% 3$ $\mathrm{ml}$ dan diekstrak dengan pelarut kloroform sebanyak $60 \mathrm{ml}$ yang diberikan sebanyak tiga kali, tiap penambahan sebanyak $20 \mathrm{ml}$ kemudian diekstraksi. Fasa organik yang diperoleh kemudian dititrasi dengan $\mathrm{Na}_{2} \mathrm{~S}_{2} \mathrm{O}_{3}$ $0,01 \mathrm{~N}$.

\section{HASIL DAN PEMBAHASAN}

\section{Aktivasi Na-Bentonit}

Aktivasi Na-bentonit dilakukan dengan tujuan untuk meningkatkan kinerja $\mathrm{Na}$-bentonit. Perlakuan awal yang dikerjakan terhadap sampel adalah mencuci Na-bentonit dengan akuades. Pencucian ini bertujuan untuk menghilangkan pengotor-pengotor organik yang ada pada Na-bentonit terutama yang menempel pada bagian permukaan $\mathrm{Na}$ bentonit. Dehidrasi dilakukan pada suhu $110^{\circ} \mathrm{C}$ sampai berat konstan untuk mengurangi kandungan air dan pengotor organik yang masih menutupi permukaan bentonit. $\mathrm{Na}$ bentonit ini kemudian diaktivasi dengan asam sulfat 1,5 M. Aktivasi dilakukan dengan tujuan untuk memperbesar luas permukaan bentonit karena berkurangnya pengotor anorganik yang menutupi pori-pori bentonit sehingga poriporinya lebih terbuka, dan ruang kosong menjadi lebih besar. Aktivasi dengan asam sulfat juga menyebabkan material bentonit terprotonasi sehingga bentonit bersifat positif.

Tujuan dari aktivasi menggunakan asam adalah untuk menukar kation yang ada pada bentonit $\left(\mathrm{Na}^{+}\right.$dan $\left.\mathrm{Ca}^{2+}\right)$ dengan ion $\mathrm{H}^{+}$dan melepaskan ion $\mathrm{Al}, \mathrm{Fe}$ dan $\mathrm{Mg}$ dan pengotorpengotor lainnya dari kisi-kisi struktur, sehingga secara fisiknya bentonit tersebut menjadi aktif [9]-[11]. Untuk keperluan tersebut asam sulfat dan asam klorida adalah zat kimia yang umum digunakan. Proses pelepasan Al dari bentonit disajikan dalam persamaan berikut ini :

$\left(\mathrm{Al}_{4}\right)\left(\mathrm{Si}_{8}\right) \mathrm{O}_{20}(\mathrm{OH})_{4}+3 \mathrm{H}^{+} \rightarrow\left(\mathrm{Al}_{3}\right)\left(\mathrm{Si}_{8}\right) \mathrm{O}_{20}(\mathrm{OH})_{2}+\mathrm{Al}^{3+}+$ $\mathrm{H}_{2} \mathrm{O} \rightarrow\left(\mathrm{Al}_{4}\right)\left(\mathrm{Si}_{8}\right) \mathrm{O}_{20}(\mathrm{OH})_{4}+6 \mathrm{H}^{+} \rightarrow$ $\left(\mathrm{Al}_{2}\right)\left(\mathrm{Si}_{8}\right) \mathrm{O}_{20}(\mathrm{OH})_{4}+2 \mathrm{Al}^{3+}+4 \mathrm{H}_{2} \mathrm{O}$

Pada spektrum bentonit terlihat adanya pita lebar pada bilangan gelombang $3439,9 \mathrm{~cm}^{-}$ 1 yang merupakan vibrasi ulur gugus $-\mathrm{OH}$ dari molekul air yang terserap pada interlayer dan memiliki ikatan hidrogen lemah dengan permukaan Si-O. Pelebaran pita ini disebabkan banyaknya molekul air yang terkandung dalam kerangka bentonit. Bilangan gelombang 1640,7 $\mathrm{cm}^{-1}$ menunjukkan vibrasi tekuk $-\mathrm{OH}$ dari Si$\mathrm{OH}$. Pita serapan pada bilangan gelombang $1038,9 \mathrm{~cm}^{-1}$ diakibatkan oleh vibrasi ulur Si-O dari gugus $\mathrm{Si}-\mathrm{O}-\mathrm{Si}$ yang teramati sebagai puncak serapan yang lebar dengan intensitas 
yang tajam. Pita serapan pada bilangan gelombang 921,2 $\mathrm{cm}^{-1}$ menunjukkan adanya vibrasi $\mathrm{OH}$ dari $\mathrm{Al}-\mathrm{OH}$ pada lapisan oktahedral. Pada gambar 1 juga terlihat perbedaan puncak gugus fungsional pada Na-bentonit dan bentonit teraktivasi asam sulfat. Pada $\mathrm{Na}$ bentonit terlihat ada puncak pada $1445,9 \mathrm{~cm}^{-1}$ dan $872,4 \mathrm{~cm}^{-1}$ tetapi tidak terdapat pada bentonit aktif. Hal ini dikarenakan terjadi pelepasan pengotor-pengotor dari kisi-kisi struktur, sehingga secara fisiknya bentonit tersebut menjadi aktif. Sementara itu mineral khas dari bentonit yaitu mineral montmorillonit tetap dipertahankan, hal ini teramati pada bilangan gelombang $1640,1 \mathrm{~cm}^{-1}$ dan $921,3 \mathrm{~cm}^{-}$ ${ }^{1}[12]$.

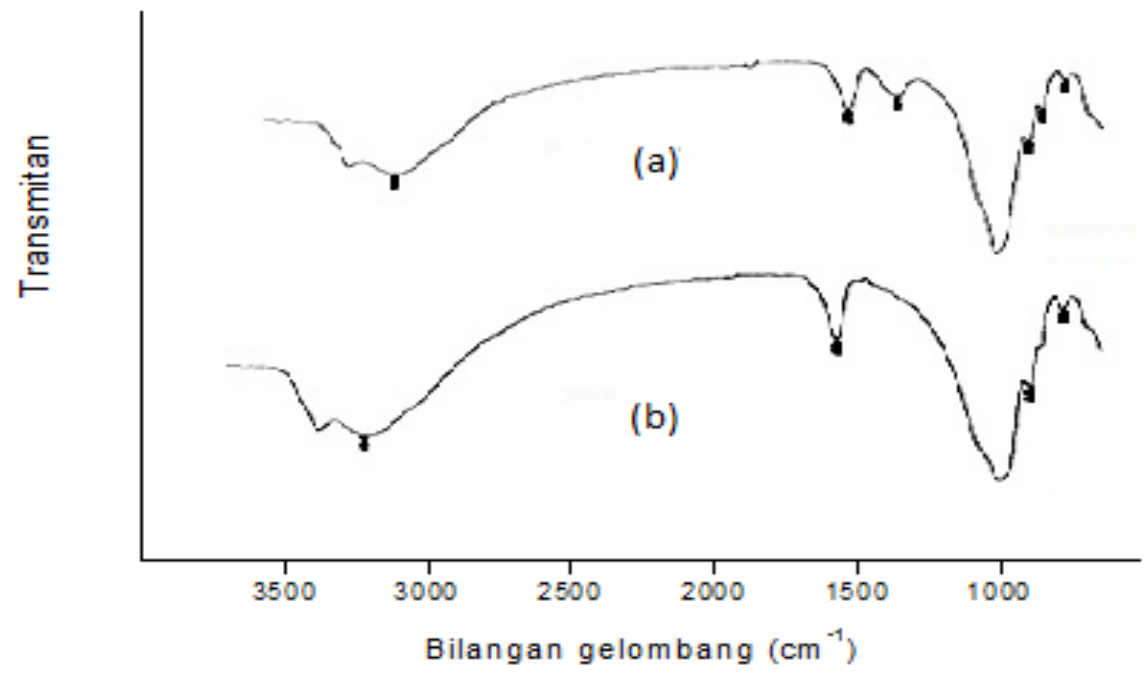

Gambar 1. Spektra IR (a) Na-bentonit, (b) bentonit teraktivasi asam sulfat

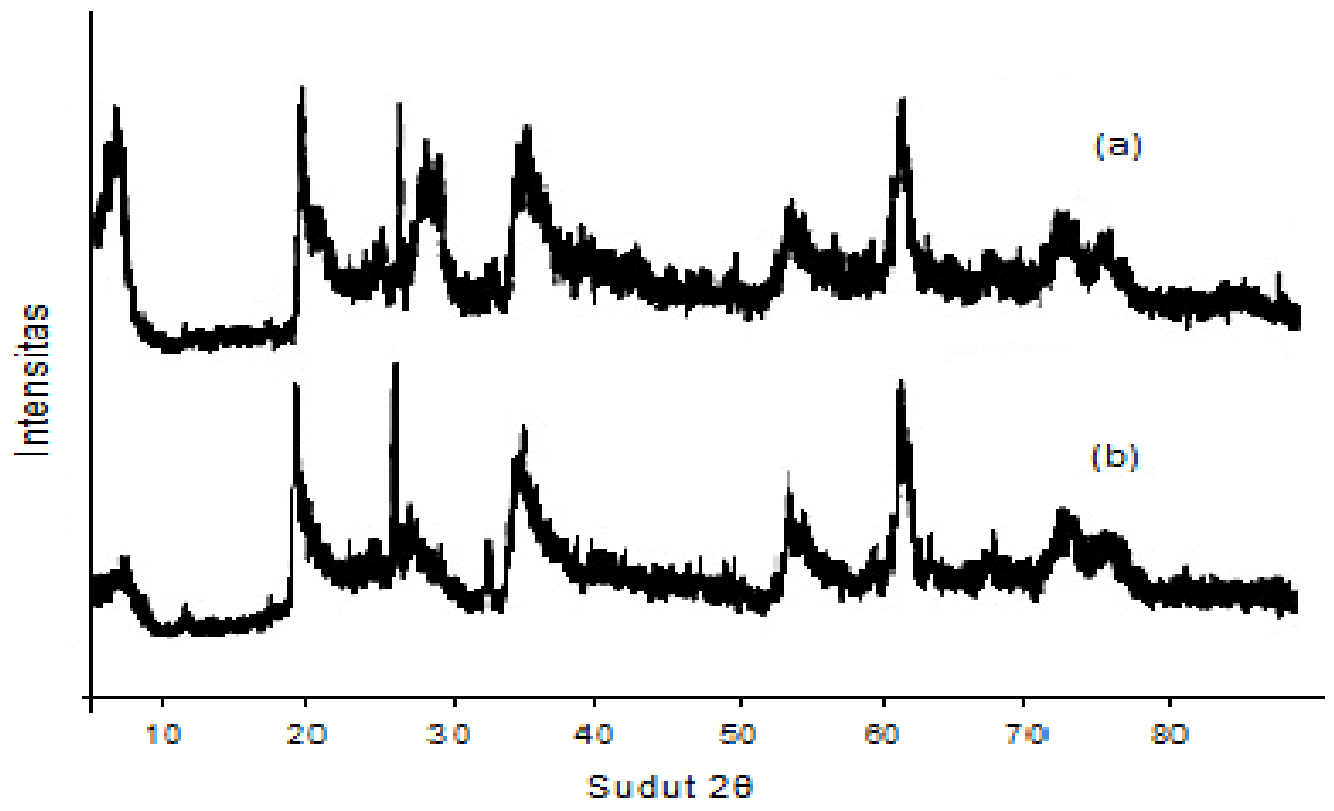

Gambar 2. Difraktogram XRD: (a) Na-bentonit; dan (b) bentonit aktif 
Pola difraktogram XRD dari Na-bentonit dan bentonit aktif terdapat pada gambar 2 . Pada gambar diatas dapat dijelaskan bahwa struktur dari Na-Bentonit dengan Bentonit aktif tidak mengalami perubahan. Hal ini terlihat pada nilai $\mathrm{d}$-spacing montmorillonit pada $\mathrm{Na}$ bentonit mempunyai nilai yang sama dengan nilai d-spacing pada bentonit aktif yaitu pada 4.4 Å. Perbedaan yang terlihat antara Nabentonit dengan bentonit aktif adalah pada nilai intensitas. Nilai intensitas bentonit aktif secara umum lebih rendah dibandingkan dengan nilai intensitas $\mathrm{Na}$-bentonit. Hal ini karena bentonit aktif lebih bersih sehingga bersifat lebih amorf. Intensitas puncak dalam suatu difaktogram memberikan gambaran tentang derajat kristalinitas suatu komponen mineral dalam bentonit. Pada gambar 2 terlihat bahwa intensitas mineral montmorllonit lebih tinggi dari pada mineral penyusun lainnya. Selain itu intensitas puncak difaktogram juga sebanding dengan konsentrasi mineralnya.

\section{Efektifitas Bentonit Aktif Sebagai Adsorben lodium}

Sebelum proses adsorpsi dilakukan, terlebih dahulu peneliti membuat larutan iodium induk dengan konsentrasi 1000 ppm. Setelah didapat larutan iodium induk, larutan tersebut diencerkan menjadi larutan kerja. Setelah larutan kerja diperoleh, dilakukan titrasi pada larutan kerja, titrasi pada larutan kerja ini digunakan untuk mengetahui perbedaan konsentrasi larutan iodium sebelum dan sesudah adsorpsi. Setelah itu proses adsorpsi dilakukan dengan cara mendispersikan 4 gram bentonit aktif kedalam larutan iodium sebanyak
$100 \mathrm{ml}$ kemudian distirer selama 15, 30, 45, 60, dan 75 menit, pengadukan menggunakan magnetik stirer bertujuan agar proses adsorpsi berlangsung secara optimal dan homogen. Adsorpsi iodium dengan bentonit diperkirakan terjadi melalui adsorpsi fisik dan adsorpsi kimia, adsorpsi fisik terjadi karena adanya gaya van der Waals pada permukaan bentonit dengan adsorbat (iodium).

Setelah proses adsorpsi selesai dilakukan pemisahan dengan cara menyaring dengan kertas saring. Filtrat yang dihasilkan ditambahkan $3 \mathrm{ml} \mathrm{H}_{2} \mathrm{SO}_{4} 10 \%$ dan $3 \mathrm{ml} \mathrm{H}_{2} \mathrm{O}_{2}$ $10 \%$, hal ini bertujuan agar terjadi oksidasi pada iodium. reaksinya

$2 \mathrm{Nal}+\mathrm{H}_{2} \mathrm{SO}_{4}+\mathrm{H}_{2} \mathrm{O}_{2} \rightarrow \mathrm{I}_{2}+\mathrm{Na}_{2} \mathrm{SO}_{4}+2 \mathrm{H}_{2} \mathrm{O} \quad$ [13]

Dari reaksi diatas dapat diketahui bahwa iodium merupakan senyawa polar. Untuk memisahkan iodium dengan senyawa lainnya dalam proses ekstraksi menggunakan pelarut kloroform, ektraksi dilakukan sebanyak tiga kali yang masing-masing menggunakan kloroform sebanyak $20 \mathrm{ml}$. Proses ekstraksi berulang ini bertujuan agar iodium yang terekstrak didapat dalam jumlah yang banyak. Fasa organik yang didapat pada proses ekstraksi kemudian dititrasi dengan natrium tiosulfat $0,01 \mathrm{~N}$ sehingga terjadi reaksi antara iodium dengan natrium tiosulfat. reaksinya:

$$
\begin{gathered}
2 \mathrm{~S}_{2} \mathrm{O}_{3}{ }^{2-}+\mathrm{I}_{2} \rightarrow 2 \mathrm{I}^{-}+\mathrm{S}_{4} \mathrm{O}_{6}{ }^{2-} \\
2 \mathrm{Na}_{2} \mathrm{~S}_{2} \mathrm{O}_{3}+\mathrm{I}_{2} \rightarrow 2 \mathrm{Nal}+\mathrm{S}_{4} \mathrm{O}_{6}{ }^{2-}
\end{gathered}
$$


Tabel 1. Hubungan Waktu Interaksi dengan Berat lodium yang Teradsorpsi

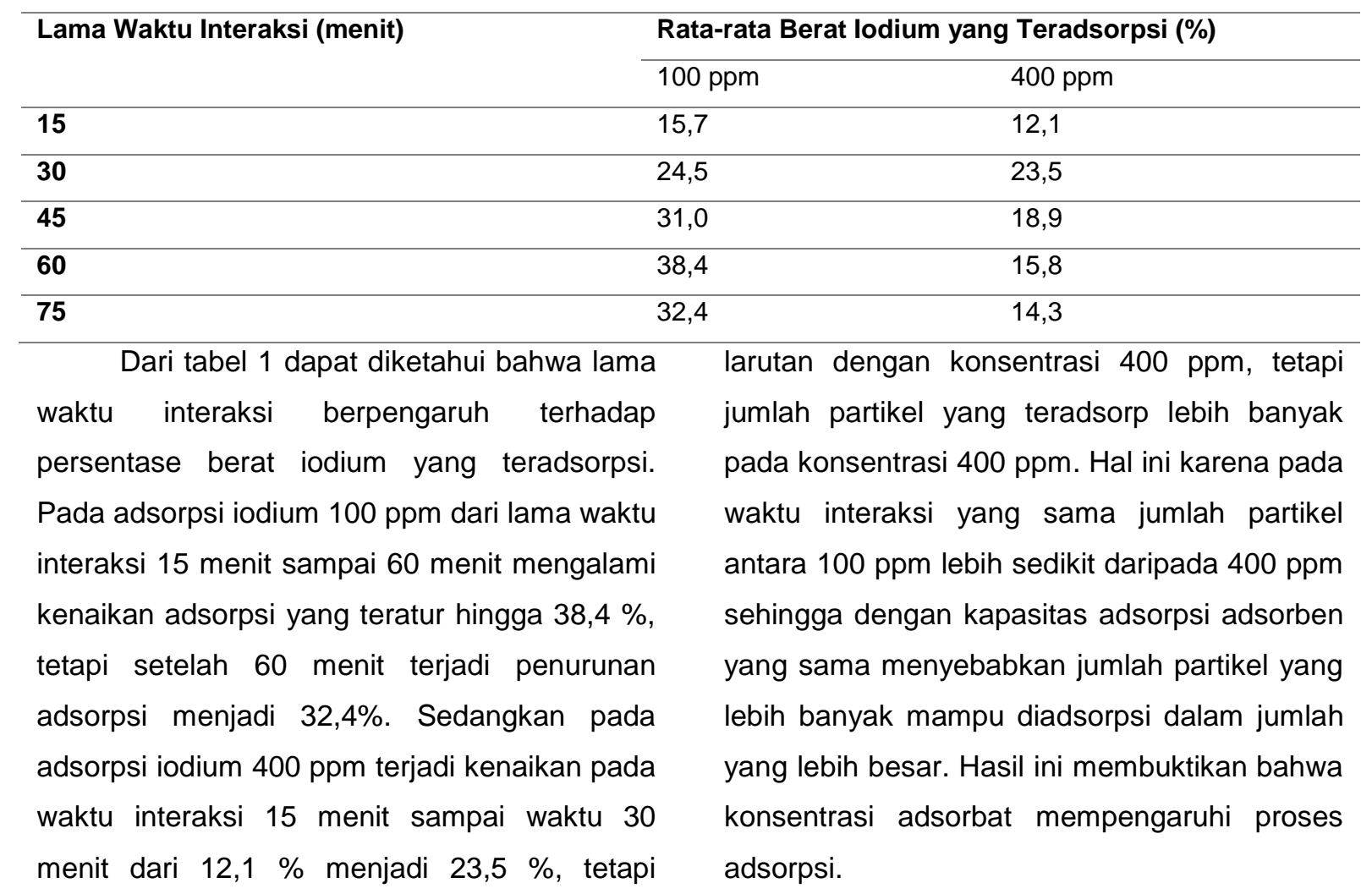
setelah 30 menit proses adsorpsi cenderung mengalami penurunan. Hal ini karena semakin lama waktu interaksi antara adsorbat dengan adsorben akan meningkatkan besarnya nilai adsorpsi, hingga pada titik tertentu kemampuan adsorben untuk melakukan adsorpsi telah jenuh. Pada keadaan ini terjadi kesetimbangan adsorpsi antara adsorbat dengan adsorben. Proses pengadukan juga akan mengakibatkan terjadinya tumbukan antara partikel adsorbat dengan partikel adsorben secara tepat dan kontinyu, sehingga ada kemungkinan adsorbat akan dilepaskan kembali oleh adsorben [14].

Dari dua konsentrasi larutan kerja yang dibuat oleh peneliti terlihat bahwa iodium dengan konsentrasi 100 ppm lebih besar presentasinya yang teradsorpsi dari pada 


\section{UCAPAN TERIMA KASIH}

Ucapan terima kasih penulis sampaikan kepada PT. Kimia Farma Watudakon Mojokerto yang telah memberikan data lapangan tentang pengolahan iodium.

\section{DAFTAR PUSTAKA}

[1] M. Toor, B. Jin, S. Dai, dan V. Vimonses, "Activating natural bentonite as a cost-effective adsorbent for removal of Congo-red in wastewater," Journal of Industrial and Engineering Chemistry., volume (21), pp. 653-661, 2015 .

[2] R. R. Pawar, Lalhmunsiama, dan H. C. Bajaj, "Activated bentonite as a low-cost adsorbent for the removal of $\mathrm{Cu}$ (II) and $\mathrm{Pb}$ (II) from aqueous solutions: Batch and column studies," Journal of Industrial and Engineering Chemistry., volume (34), pp. 213-223, 2016.

[3] A. A. Moosa, A. M. Ridha, dan I. N. Abdullha, "Chromium lons Removal from Wastewater Using Activated Iraqi Bentonite," International Journal of Innovative Research in Science, Engineering and Technology., volume (4), pp. 15-25, 2015.

[4] S. Salem, A. Salem, dan A. A. Babaei, "Preparation and characterization of nano porous bentonite for regeneration of semi-treated waste engine oil: Applied aspects for enhanced recovery," Chemical Engineering Journal., volume (260), pp. 368-376, 2015.
[5] Minto, Supeno, "Bentonit Alam Terpilar Sebagai Material Katalis/Co-Katalis Pembuatan Gas Hidrogen dan Oksigen dari Air", Disertasi, Medan: Universitas Sumatra Utara, 2007.

[6] Suarya, P, "Interkalasi tetraetil ortosilikat (teos) pada Lempung teraktifasi asam sulfat dan pemanfaatannya Sebagai adsorben warna limbah garmen", Jurnal kimia volume 4 (1), hal 43-48, 2010.

[7] Suarya, P, "Adsorpsi Pengotor Minyak Daun Cengkeh oleh Lempung Teraktivasi Asam". Jurnal Kimia. Vol 2 no 1. Hal 19-24. 2008.

[8] Napitupulu, Albert, "Impregnasi Karbon Aktif dengan Sulfida Untuk Mengikat Ion Tembaga(II) dan Kadmium(II) Didalam Air", Tesis. Medan: Universitas Sumatra Utara, 2009.

[9] Wigati, "Karakteristika Pertukaran Kation Fe(III) pada Bentonit”. Skipsi. Surabaya: Jurusan Kimia UNAIR. 1998.

[10] S. Salem, A. Salem, dan A. A. Babaei, "Application of Iranian nano-porous Ca-bentonite for recovery of waste lubricant oil by distillation and adsorption techniques," Journal of Industrial and Engineering Chemistry., volume (23), pp. 154-162, 2015.

[11] N. Belhouchat, H. Z. Boudiaf, dan C. Viseras, "Removal of anionic and cationic dyes from aqueous solution with activated organo-bentonite/sodium alginate encapsulated beads," Applied clay science., volume (135), pp. 9-15, 2017.

[12] Wijaya, Karna, Ani Setyo P, Sri Sudiono, Emi Nurrahmi, "Studi Stabilitas Termal dan Asam Lempung Bentonit". Indonesia Journal of Chemistry, Vol. 2, No. 2, hal. 20-25. 2002.

[13] Vogel, Buku Teks Analisis Anorganik Kualitatif Makro dan Semimikro, Jakarta: PT Kalman Media Pustaka, 1985.

[14] Oscik, J., Adsorption, New York: John Willey and Sons, 1982 